\title{
Medial Superior Olivary Neurons Receive Surprisingly Few Excitatory and Inhibitory Inputs with Balanced Strength and Short-Term Dynamics
}

\author{
Kiri Couchman, ${ }^{1}$ Benedikt Grothe, ${ }^{1,2}$ and Felix Felmy ${ }^{1}$ \\ ${ }^{1}$ Department of Biology II, Division of Neurobiology, Ludwig-Maximilians University, Munich, D-82152 Martinsried, Germany, and ${ }^{2}$ Bernstein Center for \\ Computational Neuroscience Munich, D-82152 Martinsried, Germany
}

\begin{abstract}
Neurons in the medial superior olive (MSO) process microsecond interaural time differences, the major cue for localizing low-frequency sounds, by comparing the relative arrival time of binaural, glutamatergic excitatory inputs. This coincidence detection mechanism is additionally shaped by highly specialized glycinergic inhibition. Traditionally, it is assumed that the binaural inputs are conveyed by many independent fibers, but such an anatomical arrangement may decrease temporal precision. Short-term depression on the other hand might enhance temporal fidelity during ongoing activity. For the first time we show that binaural coincidence detection in MSO neurons may require surprisingly few but strong inputs, challenging long-held assumptions about mammalian coincidence detection. This study exclusively uses adult gerbils for in vitro electrophysiology, single-cell electroporation and immunohistochemistry to characterize the size and short-term plasticity of inputs to the MSO. We find that the excitatory and inhibitory inputs to the MSO are well balanced both in strength and short-term dynamics, redefining this fastest of all mammalian coincidence detector circuits.
\end{abstract}

\section{Introduction}

The bipolar neurons of the medial superior olive (MSO) process interaural time differences (ITDs), a cue for localizing lowfrequency sounds sources in the azimuthal plane, using a coincidence detection mechanism (Goldberg and Brown, 1969; Yin and Chan, 1990; Brand et al., 2002). Operating on microsecond timescales, these neurons perform the fastest and most precise coincidence detection in the mammalian brain. Coincidence detection in the MSO involves the integration of a set of excitatory inputs arising from the anterior ventral cochlear nucleus, and inhibitory inputs predominantly arising from the medial nucleus of the trapezoid body (MNTB) (Fig. 1). Additionally, the lateral nucleus of the trapezoid body (LNTB) contributes a minor inhibitory input to this circuit. The temporal alignment of these inputs are vital to maintaining physiologically relevant ITD coding (Brand et al., 2002; Pecka et al., 2008).

Coincidence detector neurons employ different input strategies to establish and maintain fine temporal precision. Octopus cells (Golding et al., 1995; Oertel et al., 2000) and neurons in the chick nucleus laminaris (NL) (Reyes et al., 1996; Agmon-Snir et al., 1998; Kuba et al., 2002, 2006; Cook et al., 2003) integrate a

Received April 7, 2010; revised 0ct. 13, 2010; accepted 0ct. 25, 2010.

This project was funded by the Deutsche Forschungsgemeinschaft (DFG) SFB870. K.C. was supported by the DFG Research Training Group (GRK) 1091 and the Graduate School of Systemic Neuroscience (GSN ${ }^{\text {LMU }}$ ). We thank Dr. Holger Taschenberger for generously providing the mini detection routine, Dr. Olga Alexandrova for providing the digital extraction, and Claudia Aerdker for technical support regarding the immunohistochemistry. Thanks also to Dr. Ida Siveke for early discussions.

Correspondence should be addressed to Dr. Felix Felmy, Department of Biology II, Division of Neurobiology, Ludwig-Maximilians University, Munich, Großhadernerstrasse 2, D-82152 Martinsried, Germany. E-mail: felmy@zi.biologie.uni-muenchen.de.

DOI:10.1523/JNEUROSCI.1760-10.2010

Copyright $\odot 2010$ the authors $\quad 0270-6474 / 10 / 3017111-11 \$ 15.00 / 0$ large number of small, independent fiber inputs. In contrast, the endbulb of Held synapses on bushy cells operate with a minimal number of large excitatory input fibers (2-3 per cell) (Joris et al., 1994; Xu-Friedman and Regehr, 2005). In all of these coincidence detector circuits, synaptic short-term depression (STD) is key to maintaining temporal precision (Kuba et al., 2002; Cook et al., 2003; Yang and Xu-Friedman, 2008). As yet, the synaptic basis of the fastest of all mammalian coincidence detector nuclei, the MSO, is unknown. This lack of precise biophysical data on mammalian binaural coincidence detection has resulted in computational models with diverse estimates of input number and strength (Kempter et al., 1998; Brand et al., 2002; Cook et al., 2003; Grau-Serrat et al., 2003; Kuba et al., 2006; Ashida et al., 2007).

Neurons in the MSO have a low input resistance (Magnusson et al., 2005; Scott et al., 2005; Chirila et al., 2007), suggesting that large synaptic currents are required for action potential (AP) generation and for inhibitory inputs to have a significant impact. This assumption is supported by ultrastructural evidence for multiple active zones on both excitatory and inhibitory synaptic boutons contacting the MSO (Clark, 1969; Lindsey, 1975; Kiss and Majorossy, 1983; Brunso-Bechtold et al., 1990; Kapfer et al., 2002). Furthermore, all upstream synapses of this circuit are calyceal, and a large synapse on the circuit's output neuron would maintain time delay information by reducing synaptic jitter. In vivo studies show that MSO neurons can fire at very high rates, locking precisely to the phase of pure tones (Brand et al., 2002). Thus, given this circuit relies on temporally precise inhibition and excitation (Brand et al., 2002; Pecka et al., 2008), we expect these inputs to behave similarly during high-frequency stimulation in vitro. Therefore, we hypothesize that the recruitment of a 


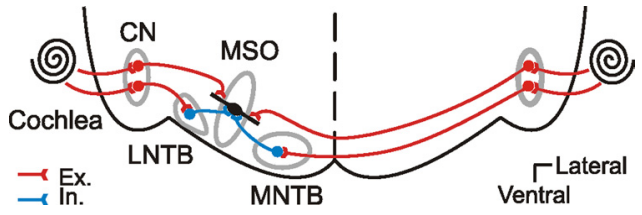

Figure 1. Schematic drawing of the binaural coincidence detection pathway for lowfrequency sounds in the mammalian brainstem. Neurons in the MSO receive bilateral excitatory and inhibitory inputs via the cochlear nuclei (CN) and the MNTB and LNTB, respectively.

set of strong and fast synaptic inputs establishes the presynaptic basis for the exquisite coincidence detection in MSO neurons.

\section{Materials and Methods}

Slice preparation. All experiments complied with institutional guidelines, national and regional laws. Slices were prepared from male and female Mongolian gerbils (Meriones unguiculatus). Animals were decapitated and brains were removed in dissection solution containing (in $\mathrm{mM}$ ) 50 sucrose, $25 \mathrm{NaCl}, 25 \mathrm{NaHCO}_{3}, 2.5 \mathrm{KCl}, 1.25 \mathrm{NaH}_{2} \mathrm{PO}_{4}, 3 \mathrm{MgCl}_{2}, 0.1$ $\mathrm{CaCl}_{2}, 25$ glucose, 0.4 ascorbic acid, 3 myo-inositol and $2 \mathrm{Na}$-pyruvate ( $\mathrm{pH} 7.4$ when bubbled with $95 \% \mathrm{O}_{2}$ and $5 \% \mathrm{CO}_{2}$ ). Subsequent to the removal of the brain, horizontal or transverse brainstem slices containing the MSO and the MNTB were taken with a VT1200S vibratome (Leica). In the horizontal preparation the most ventral section was discarded to restrict the recordings to the low-frequency region. Slices were incubated in recording solution (same as slice solution but with $125 \mathrm{~mm} \mathrm{NaCl}$, no sucrose and $2 \mathrm{mM} \mathrm{CaCl}_{2}$ and $1 \mathrm{mM} \mathrm{MgCl}_{2}$ ) at $36^{\circ} \mathrm{C}$ for $45 \mathrm{~min}$, bubbled with $5 \% \mathrm{CO}_{2}$ and $95 \% \mathrm{O}_{2}$.

Electrophysiology. The electrophysiological properties of MSO neurons and the time course of their inputs are developmentally regulated and a dependency on the recording temperature has been reported (Smith et al., 2000; Magnusson et al., 2005; Scott et al., 2005; Chirila et al., 2007). To obtain quantitative estimates comparable to the function described by in vivo physiology, we restricted our in vitro circuit analysis to acute horizontal brain slices (90-120 $\mu \mathrm{m}$ thickness) from adult [postnatal day (P) 60-100] Mongolian gerbils. Unless otherwise stated, all experiments were performed at near physiological temperature $\left(34-36^{\circ} \mathrm{C}\right)$, maintained by an in-line (SF-28) and bath chamber heater (PH-1; Warner Instruments, Biomedical Instruments) and monitored with a temperature probe placed directly by the slice. After incubation slices were transferred to a recording chamber attached to a microscope (BX50WI; Olympus) equipped with gradient contrast illumination (Luigs and Neumann) and continuously perfused with recording solution. Cells were visualized and imaged with a TILL Photonics system composed of an Imago CCD camera, a monochromator and its control unit. Voltageclamp whole-cell recordings were performed using an EPC10/2 amplifier (HEKA Elektronik) on visually identified MSO neurons. Access resistance was compensated to a residual of 2.5-3 $\mathrm{M} \Omega$; data were acquired at $20-50 \mathrm{kHz}$ and filtered at $3-4 \mathrm{kHz}$. Synaptic currents were evoked by local stimulation of available afferent fibers with a glass electrode filled with incubation solution. We then probed the vicinity $(40-150 \mu \mathrm{m})$ of a patched MSO neuron with this monopolar stimulation electrode for stably activatable input sites. To stimulate fibers a voltage pulse was generated by the EPC10/2 amplifier (HEKA Elektronik) and postamplified 10 times by a linear stimulus isolator (A395; World Precision Instruments). All protocols were repeated at least 3 times for each cell. To allow for full recovery of the response, repetitions of single pulses were delivered in $7 \mathrm{~s}$ intervals and stimulus trains with intervals of 15-20 s.

Glycinergic IPSCs were recorded in the presence of DNQX $(20 \mu \mathrm{M})$, D-APV $(50 \mu \mathrm{M})$ and SR95531 (10 $\mu \mathrm{M})$. AMPA receptor (AMPA-R)mediated glutamatergic EPSCs were isolated using D-APV $(50 \mu \mathrm{M})$, strychnine $(0.5 \mu \mathrm{M})$ and SR95531 $(10 \mu \mathrm{M})$. The intracellular solution used to record EPSCs was (in mM): 130 Cs-gluconate, 10 Cs-HEPES, 20 tetraethylammonium (TEA)-Cl, $3.3 \mathrm{MgCl}_{2}, 2 \mathrm{Na}_{2}$-ATP, $0.3 \mathrm{Na}_{2}$-GTP, 3 $\mathrm{Na}_{2}$-phosphocreatine, 5 Cs-EGTA and 5 QX-314 [N-(2,6-dimethylphenylcarbamoylmethyl)triethylammonium bromide] with 50-70 $\mu \mathrm{M}$ Alexa Fluor 488 and for IPSCs (in mM): 105 Cs-gluconate, $26.7 \mathrm{CsCl}, 10$
Cs-HEPES, 20 TEA-Cl, $3.3 \mathrm{MgCl}_{2}, 2 \mathrm{Na}_{2}$-ATP, $0.3 \mathrm{Na}$-GTP, $3 \mathrm{Na}_{2}$ phosphocreatine, 5 Cs-EGTA, and 5 QX-314 with 50-70 $\mu \mathrm{M}$ Alexa Fluor

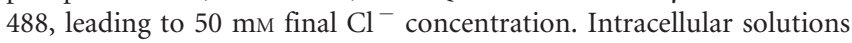
were adjusted to $\mathrm{pH} 7.2$ with $\mathrm{CsOH}$. For current-clamp recordings the internal solution consisted of (in $\mathrm{mM}$ ): $145 \mathrm{~K}$-gluconate, $5 \mathrm{KCl}, 2 \mathrm{Mg}$ ATP, 2 K-ATP, $0.3 \mathrm{Na}_{2}$-GTP, $7.5 \mathrm{Na}_{2}$-phosphocreatine, 15 HEPES and 5 K-EGTA with 50-70 $\mu \mathrm{M}$ Alexa Fluor 568. In general, no liquid junction potential correction was made. The conductance $(G)$ of synaptic currents was calculated using the equation $G=I / V$, where $I$ is the recorded current (both mPSC and PSC) and $V$ is the driving force. Since cells were held at $-60 \mathrm{mV}$ during recordings we calculate a $70 \mathrm{mV}$ driving force for AMPA-R-mediated currents. For glycinergic $\mathrm{Cl}^{-}$currents we measured the reversal potential at $\sim-15 \mathrm{mV}$, resulting in a $45 \mathrm{mV}$ driving force (data not shown).

Electroporation. Single-cell electroporation was performed as described recently (Rautenberg et al., 2009) on transverse brain slices (240 $\mu \mathrm{m}$ thickness) containing the MNTB and MSO of P20-P25 gerbils. A patch pipette (size corresponding to $4-5 \mathrm{M} \Omega$ ), loaded with either Alexa FluorTM 488 sodium hydrazide or its 568 analog ( $1 \mathrm{~mm}$, Invitrogen) was pressed onto the surface of visually identified MSO neurons and a single 18- to 22-ms-long voltage pulse (15-22 V) was applied. The voltage pulse was generated by an EPC10/2 amplifier (HEKA Elektronik) and postamplified 10 times by a linear stimulus isolator (A395; World Precision Instruments). After $\sim 1 \mathrm{~min}$ the dye appeared evenly distributed within the cell soma and dendrites. During electroporation the slices were perfused continuously with incubation solution at room temperature. Slices containing labeled cells were fixed in $4 \%$ paraformaldehyde and left overnight. After two 5 min washes with PBS ( $\mathrm{pH}$ 7.4), sections were stained for Nissl. After confocal reconstruction of the area in question, the fibers were traced off-line from their terminus in the MSO to the originating cell in 3D through high-resolution $Z$-stacks.

Immunohistochemistry and confocal microscopy. Immunohistochemistry was performed in tissue from animals aged between P22 and P30. The animals were anesthetized ( $0.5 \%$ chloral hydrate, $0.2 \mathrm{ml} / 10 \mathrm{~g}$ of body weight) and perfused with PBS containing $0.1 \%$ heparin and $155 \mathrm{~mm}$ $\mathrm{NaCl}$ for $\sim 10 \mathrm{~min}$ before switching the perfusion to $4 \%$ paraformaldehyde. After a 45 min perfusion the brains were removed and postfixed overnight. Brains were washed twice in PBS and coronal brain slices of 40-60 $\mu \mathrm{m}$ thickness were taken with a VT1000S vibratome (Leica). Standard immunohistochemistry procedures were performed on freefloating slices using primary antibodies (ABs) for calretinin (CR) (monoclonal anti-mouse $\mathrm{AB}$, clone $6 \mathrm{~B} 3$ or polyclonal anti-rabbit $\mathrm{AB}$, catalog $\# 7699 / 3 \mathrm{H}$; Swant), calbindin (CB) (monoclonal anti-mouse AB, clone 300 , polyclonal anti-rabbit $\mathrm{AB}$, catalog \#CB38a; Swant), parvalbumin (PV) (polyclonal anti-rabbit AB, catalog \#PV 28; Swant), glycine transporter 2 (GlyT2) (polyclonal anti-guinea pig, catalog \#AB1733; Millipore), synaptic vesicle protein 2 (SV2) (monoclonal mouse AB; Developmental Studies Hybridoma Bank, University of Iowa, Iowa City, IA), Rab3A (monoclonal anti-mouse AB, clone 42.2; Synaptic Systems) and microtubule-associated protein 2 (MAP-2) (polyclonal anti-chicken $\mathrm{AB}$, catalog \#CH22103; Neuromics, Acris Antibodies). In some cases Nissl-i-red was used instead of MAP-2 staining to delineate the somatic region of neurons. Secondary ABs were applied the following day for $2 \mathrm{~h}$ at room temperature. These were conjugated with either Alexa Fluor 488, Alexa Fluor 633 (Invitrogen) or Cy3 (Dianova). Slices were mounted in Vectashield medium (H-100; Vector Laboratories Inc., AXXORA) and confocal scans were taken with a Leica SP System. Images were acquired with a $25 \times$ or $63 \times$ objective $(0.75$ or 1.32 numerical aperture, respectively), leading to a pixel size between $781 \mathrm{~nm}^{2}$ and $310 \mathrm{~nm}^{2}$.

Data and statistical analysis. Image stacks were processed with ImageJ, MetaMorph (Universal Imaging Corp., Visitron Systems GmbH), and Neurolucida (MBF Bioscience) to extract varicosity number and synaptic number by eye. For Figure 7 (see below), the acquired images were further processed in NIH Image $1.37 \mathrm{k}$ (National Institutes of Health) as described by Werthat et al. (2008). Individual cell processes visible on each optical section of MAP-2 staining were followed through the stack and labeled with the paintbrush tool. Subsequently, the region outside the paintbrush label was digitally deleted. We refer to this process as digital extraction. Currents were analyzed in IGOR Pro (WaveMetrics 
A
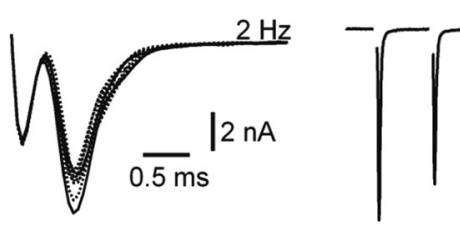

$\sqrt{\sqrt{\sqrt{\mid}}} \underset{\frac{1}{20 \mathrm{~ms}}}{\mid 2 \mathrm{nA}}$

B


C

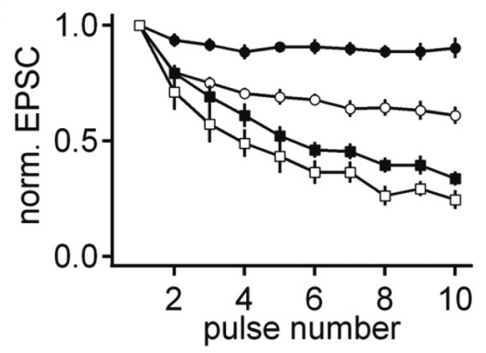

$\mathrm{E}$



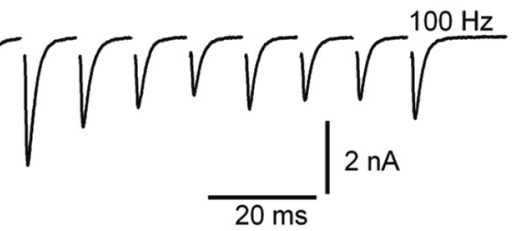

D

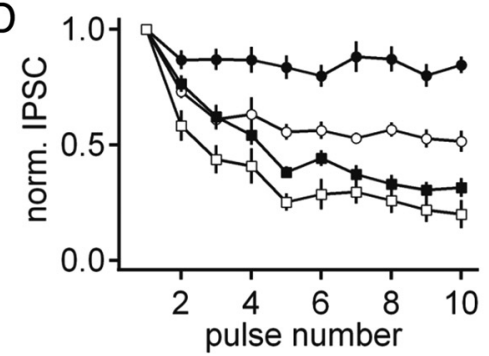

$\mathrm{F}$



G

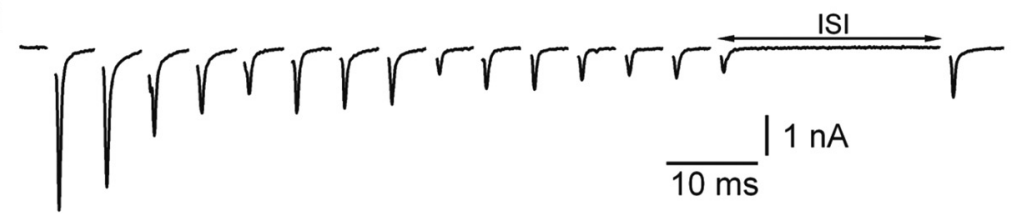

$\mathrm{H}$

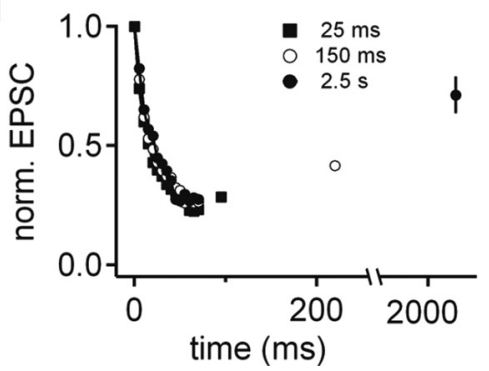

I

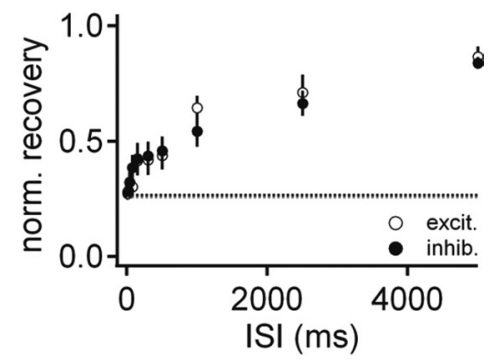

Figure 2. Short-term plasticity of excitatory and inhibitory inputs to MSO neurons. $A$, Example of excitatory AMPA-Rmediated responses to 10 stimulations at low $(2 \mathrm{~Hz}$, left) and high $(100 \mathrm{~Hz}$, right) frequency. Left, solid lines represent the response to the first and last stimulus. $\boldsymbol{B}$, Same as $\boldsymbol{A}$ but for inhibitory, glycinergic currents. $\boldsymbol{C}$, Normalized excitatory response profile to different stimulation frequencies. From top to bottom, filled circles, $0.5 \mathrm{~Hz}$; open circles, $2 \mathrm{~Hz}$; filled squares, $100 \mathrm{~Hz}$; open squares, $300 \mathrm{~Hz}$. D, Same as C but for inhibitory responses. $\boldsymbol{E}$, Steady-state depression of EPSCs (open symbols; $n=8-9$ ) and IPSCs (solid symbols; $n=10-13$ ) as a function of stimulation frequency. $\boldsymbol{F}$, Kinetics of depression of EPSCS and IPSCS (same symbols as in $\boldsymbol{E}$ ) as a function of stimulation frequency. $\tau_{\text {depr. }}$ was determined by a single exponential fit to the response profile of each stimulation frequency from each cell. $\boldsymbol{G}$, Example of EPSC response to the stimulus paradigm used to determine the recovery from depression. Fifteen pulses at $200 \mathrm{~Hz}$ were followed by a test pulse at differing ISIs. $\boldsymbol{H}$, Normalized excitatory responses to three ISIs as a function of stimulus time. $\boldsymbol{I}$, The recovery from depression of excitation (closed symbols; $n=9$ ) and inhibition (open symbols; $n=9$ ). Dotted lines indicate baseline depression reached at steady state after 15 pulses applied at $200 \mathrm{~Hz}$, gray for EPSCs, black for IPSCs.

Inc.). Miniature PSCs were extracted by a custom written template matching routine provided by Dr. Holger Taschenberger (MaxPlanck-Institute for Biophysical Chemistry Göttingen, Germany) (Taschenberger et al., 2005). Results are presented as mean \pm SEM. Statistical significance was determined using Student's $t$ test with a significance threshold of $p<0.05$.

\section{Results}

To allow for a comparison with in vivo studies, our in vitro electrophysiology was performed on mature gerbils (2-3 months of age) and carried out at near physiological temperature $\left(34-36^{\circ} \mathrm{C}\right)$.

\section{A balance between excitatory and inhibitory short-term plasticity at adult MSO synapses}

To test for a balance between excitatory and inhibitory inputs on the synaptic level, we evoked pharmacologically isolated AMPA-R- and glycine-R-mediated synaptic currents in MSO neurons in whole-cell voltage-clamp. We applied 10pulse fiber stimulation trains at frequencies ranging from $0.5-300 \mathrm{~Hz}$. Examples of $2 \mathrm{~Hz}$ and $100 \mathrm{~Hz}$ trains of AMPA-Rmediated EPSCs are shown in Figure $2 A$. Figure $2 B$ shows the same stimulation frequencies for glycinergic IPSCs. We consistently found pronounced STD, calculated from first-peak normalized trains of EPSCs and IPSCs, in a frequencydependent manner (Fig. 2C,D). To compare the STD between EPSCs and IPSCs, we first analyzed the steady-state depression (Fig. $2 E ; n=8-9$ for EPSC and $n=$ $10-13$ for IPSC). We note here that in some cells the depression curves could not be unambiguously analyzed at high frequencies. Nevertheless, both types of inputs depress similarly over the frequency range tested, depressing already at low frequencies of $0.5 \mathrm{~Hz}(\sim 10 \%)$ and reaching $\sim 70 \%$ of depression from initial values at stimulation frequencies above $200 \mathrm{~Hz}$.

To further assess similarities in STD between excitatory and inhibitory inputs we analyzed the kinetics of depression. First we plotted, for each cell, the averaged PSC peaks from the stimulus trains against pulse number, and fit the decay with an exponential function. The population average as a function of stimulation frequency is shown in Figure 2F. Both excitatory and inhibitory inputs depress with similar kinetics. During low-frequency stimulation maximal depression is reached after 2-3 stimulation pulses, and at higher frequencies both input types display a relative deceleration into the depression 
( $\sim 4$ pulses), which is overcome at the highest stimulation frequencies tested (Fig. $2 F$ ).

We next investigated the apparent recovery from depression for excitatory and inhibitory inputs. We used a $200 \mathrm{~Hz}$ train of 15 pulses to depress the synapses into steady state and applied a test pulse at varying interstimulus intervals (ISIs) ranging from $10 \mathrm{~ms}$ to $5 \mathrm{~s}$ (Fig. $2 G, H$ ). The ISIs used were selected to ensure that majority of the time course of the recovery from depression was detected. At the end of the stimulus train the EPSCs $(n=9)$ and IPSCs $(n=9)$ depressed to an average of $\sim 26 \%$ of the initial value (Fig. $2 I$, dotted line), and both input types recovered with a similar profile (Fig. 2I). After the longest ISI of $5 \mathrm{~s}$, EPSCs recovered to $87 \pm$ $4 \%$ and IPSCs to $84 \pm 3 \%$ of their initial values. Together these data indicate that the apparent short-term plasticity (STP) of excitatory and inhibitory inputs to MSO neurons is the same. Since we rule out a significant postsynaptic contribution to excitatory STD from either saturation or desensitization (supplemental Fig. S1, available at www.jneurosci.org as supplemental material) it is likely that these similarities are expressed presynaptically.

\section{Size and strength of excitatory fibers to MSO neurons}

As stated, we hypothesize that single fibers to MSO neurons should convey a substantial input. Input size and/or strength can be defined as the quantal content $(m)$ of vesicles released by a presynaptic $\mathrm{AP}$, or as its corresponding conductance. More dynamically, synaptic strength can be expressed as release probability $(p)$, if the number of releasable vesicles (the pool: $n$ ) is known. We therefore investigate the strength of synaptic inputs to MSO neurons by estimating the quantal, fiber and pool size of excitatory inputs.

Spontaneous EPSCs were recorded (Fig. 3A), and extracted for each cell to generate a frequency histogram of peaks (Fig. 3B). This was fit with a Gaussian function (Fig. $3 B$ ) to determine the mean peak amplitude and the coefficient of variation $(\mathrm{CV})$ of these spontaneous EPSCs. These events had an average peak of $53 \pm 0.3$ pA $(n=13)$ with a CV of $0.46 \pm 0.03$. These values were not significantly different from miniature EPSCs (mEPSCs) recorded in the presence of TTX ( $n=6, p>0.05$, data not shown). Thus, in the following the spontaneous EPSCs are regarded as mEPSCs. In the cells where spontaneous EPSCs were recorded $(n=13)$, we evoked EPSCs with decreasing stimulus intensities (10 or $5 \mathrm{~V}$ steps from 80 to $0 \mathrm{~V}$ ), to estimate the fiber size. We routinely obtained step-like changes in the amplitude of evoked EPSCs (Fig. 3C,D), and for each cell estimated the number of steps, the total current, and the average step size of the evoked EPSCs (Fig. $3 D$ arrows, $E)$. Since there were no significant differences $(p>$

A

$\mathrm{H}$

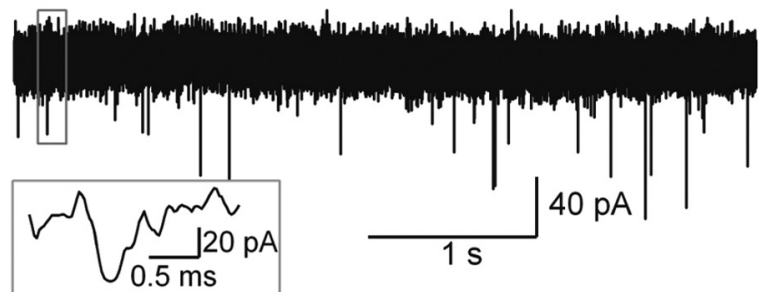

B



E
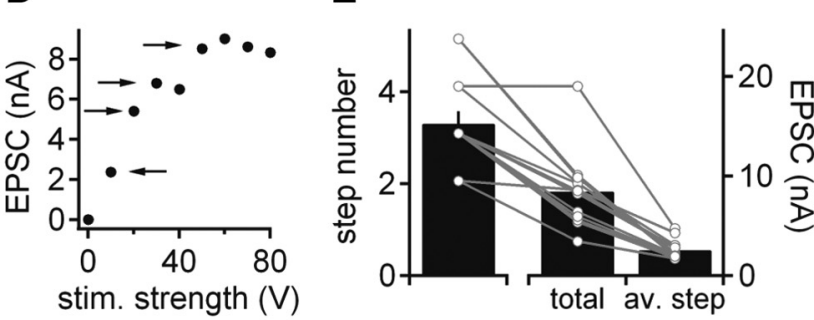

G
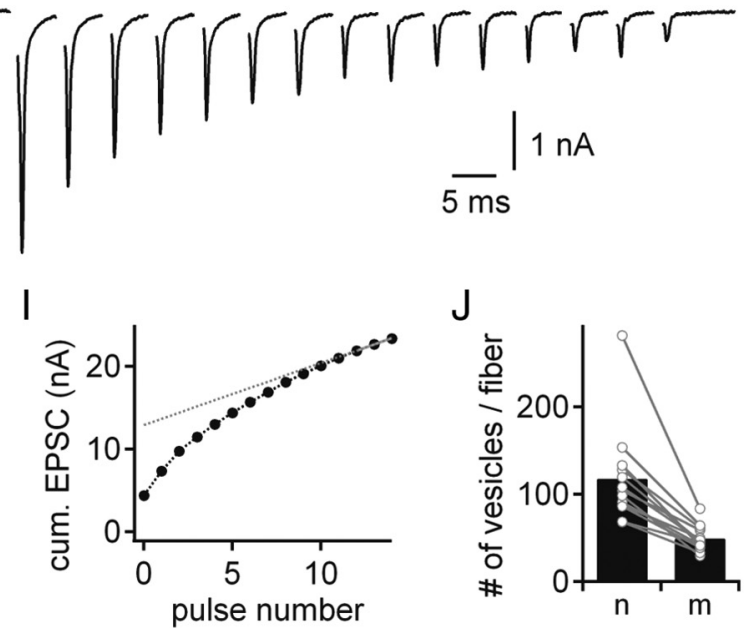

Figure 3. Determination of the excitatory input strength. All sample data traces are from one cell. $\boldsymbol{A}$, Recording of $\mathrm{mEPSCS}$. Inset shows a single enlarged mEPSC. $\boldsymbol{B}, \mathrm{mEPSC}$ peak distribution of the same cell as in $\boldsymbol{A}$, Solid line corresponds to a Gaussian fit. $\boldsymbol{C}$ Sample traces of EPSCs evoked at different stimulation intensities. D, EPSC amplitude as a function of stimulation strength from the estimated step number, the total maximal current, and the calculated average current for an average step are shown for each graph. G, Example of pool depletion protocol; 15 pulses applied at $200 \mathrm{~Hz}$. $\boldsymbol{H}$, EPSC amplitude as a function of pulse number of the last 3 pulses (gray solid line) was used to estimate the total available vesicle pool (dotted line). $\boldsymbol{J}$, The estimated average pool of vesicles for an average excitatory fiber $(n)$ and the corresponding number of vesicles released by an average single fiber $(m)$. Open symbols correspond to single-cell values, underlying bar graphs represent the population average $(n=13)$.

$0.05)$ between the fiber properties estimated using 10 and $5 \mathrm{~V}$ stimulation intensity increments, the data were pooled. The total current that could be elicited at a given stimulation site ranged between 3.5 and $19 \mathrm{nA}(8.45 \pm 1.09 \mathrm{nA}$, with a SD of $3.7 \mathrm{nA} ; n=$ 13) from single average step sizes of between 2 and $8.8 \mathrm{nA}$. The average fiber current for a given cell was calculated by dividing the maximal evoked current by the number of estimated steps (average step number $3.3 \pm 0.3$ with a range between 2 and 5 and a SD of 0.95 ; Fig. $3 E$ ), yielding an average EPSC per fiber of $2.59 \pm$ $0.28 \mathrm{nA}$. This number was additionally confirmed with a classical minimal stimulation experiment $(2.13 \pm 0.64 \mathrm{nA}$; supplemental Fig. S2, available at www.jneurosci.org as supplemental material). From all experiments where an average fiber size was esti- 

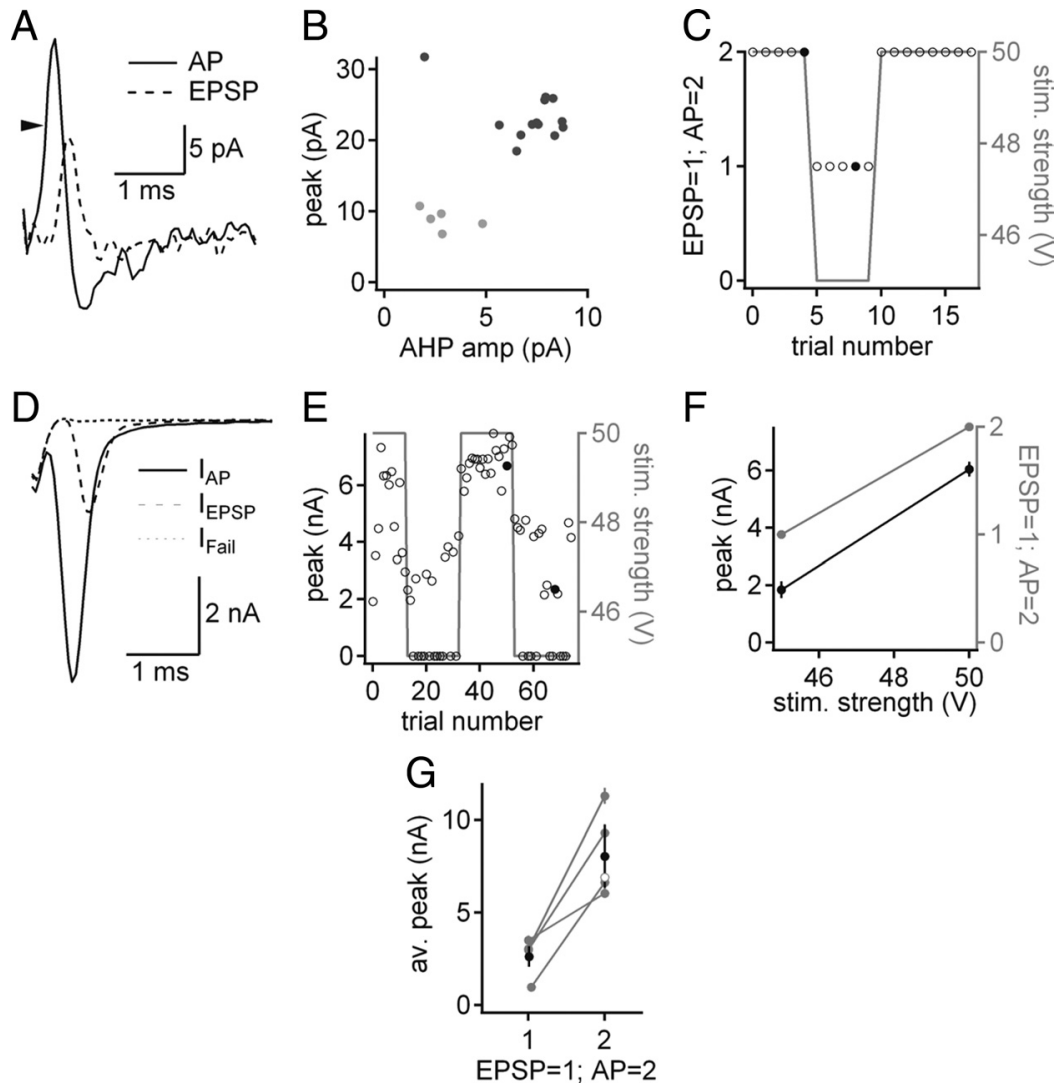

Figure 4. Functional consequences of large excitatory fibers. $A, 0$ n-cell recording of synaptically evoked responses at different stimulation intensities. Arrow indicates inflection during rise of the largest response type (AP event). $B$, Plot of peak vs AHP amplitude for all currents recorded from this cell. Black circles were classified as AP, gray circles as EPSP events. C, Event type as a function of trial number (round symbols). Stimulation strength is shown as a solid gray line. Filled symbols correspond to the traces shown in $\boldsymbol{A}$. $\boldsymbol{D}$, Whole-cell voltage-clamp response of the same cell, stimulation site and strength as in $\boldsymbol{A}-\boldsymbol{C}$. $\boldsymbol{E}$, EPSC peak amplitude and the corresponding stimulation strength are plotted as a function of trial number. Solid symbols correspond to the traces shown in $\boldsymbol{D}$. $\boldsymbol{F}$, Average EPSC peak amplitude and event type of this example cell given as a function of stimulation strength. $\boldsymbol{G}$, Average EPSC amplitude that corresponds to either EPSP or AP events. Gray symbols correspond to single cells; black symbols represent the population average $(n=5)$. Open symbol represents one cell where no EPSP events could be isolated (i.e., all trials were AP events).

mated the overall average fiber size was $2.46 \pm 0.26 \mathrm{nA}(n=18)$ with a SD of $1.09 \mathrm{nA}$. We can now infer the average quantal content of an excitatory fiber targeted to MSO neurons by dividing the average fiber size by the MEPSC quantal size for each cell. In order for this relationship to hold, it is important that transmitter release upon stimulation is phasic, as asynchronous release will lead to an underestimate of the fiber quanta. We find that the decay time of both mEPSCs $(215 \pm 11 \mu \mathrm{s})$ and maximum evoked EPSCs $(271 \pm 17 \mu \mathrm{s})$ were similar (Fig. $3 F$ ) indicating highly phasic release. Thus the average quantal content of an excitatory fiber could be readily estimated at $50 \pm 4$ vesicles (Fig. 3J, $n=6$ ).

In the same cells we also estimated the average size of the apparent pool of vesicles. To do so, we applied a 15 pulse stimulation train at $200 \mathrm{~Hz}$ (Fig. $3 G$ ) and determined an average EPSC depression curve (Fig. $3 \mathrm{H}$ ). We plotted the cumulative peak EPSC (Fig. 3I), and a linear fit to the steady state was backextrapolated to the $y$-intercept to estimate the current that would be elicited from the release of all physiologically available and readily releasable vesicles (Schneggenburger et al., 1999; Oleskevich et al., 2004). Since we know for each cell the number of activated fibers and the mean quantal size, we can calculate the average apparent pool of vesicles per fiber by dividing the maximal releasable current by the fiber number and the quantal size.
On average, we find an apparent pool size for a given excitatory fiber of $118 \pm 16$ vesicles (Fig. $3 J$ ). In addition, the average release probability, $0.45 \pm 0.03$, was estimated from the size of the vesicle pool and the quantal content (Schneggenburger et al., 1999; Oleskevich et al., 2004).

So far we have provided an estimate for the lower bound of the total excitatory presynaptic strength. To determine the physiological postsynaptic impact of these excitatory inputs, we next investigated the number of fibers required for AP generation in MSO neurons. We were able to obtain both on-cell and whole-cell recordings from the same neurons and measure the size of pharmacologically isolated AMPA-R-mediated currents that correlate with AP generation in adult MSO neurons.

In on-cell configuration we located a stable, phasic stimulation site and varied the stimulation intensity (Fig. $4 A$ ). In the example in Figure 4, a $45 \mathrm{~V}$ stimulus elicited "EPSP" waveforms with a small peak and afterhyperpolarization (AHP) amplitude. A $50 \mathrm{~V}$ stimulus intensity reliably elicited larger voltage deflections, exhibiting a small kink in the rising phase (Fig. $4 A$, arrow), a faster repolarization and a larger AHP amplitude. To classify these events, we plotted, for each cell, the peak vs AHP amplitude of the voltage deflections (Fig. 4B). According to their clustering in this plot, we separated these different waveforms as fail, EPSP, and AP accordingly (Fig. 4B,C). Plotting the elicited event type and the stimulation strength against the trial number for the example cell in Figure 4 revealed that AP events occur at $50 \mathrm{~V}$ stimulation strength and EPSP events occur at $45 \mathrm{~V}$ (Fig. 4C). Once a stimulation threshold for evoking AP events was established in the on-cell configuration, we broke into the cell and recorded the AMPA-R-mediated EPSCs elicited by the same stimulus intensities at the same stimulation site in whole-cell voltage-clamp mode. We found step-like increases in EPSC amplitude that we termed accordingly $I_{\text {fail }}, I_{\mathrm{EPSP}}$, and $I_{\mathrm{AP}}$ (Fig. 4D). When plotting the EPSC peak amplitude and the event type as a function of the stimulation strength the EPSCs between 2 and $5 \mathrm{nA}$ correlate predominantly with EPSP events. For the example cell (Fig. 4) the fiber failed to be activated in some stimulation trials during the recordings in whole-cell mode. To reliably elicit AP events only, a $6 \mathrm{nA}$ EPSC was required. In a total of 5 such recordings, EPSP events were correlated to an average EPSC peak of $2.6 \pm 0.5 \mathrm{nA}$ (Fig. $4 G, n=4$ ). To elicit an AP event, an average EPSC of $8.0 \pm 1.7 \mathrm{nA}$ was evoked with the same stimulus intensity (Fig. $4 G, n=5$ ). In one cell no EPSP events could be obtained, consistent with the fact that no EPSC smaller than $5.2 \pm 0.1 \mathrm{nA}$ could be elicited (Fig. 4G, open circle). On average, the EPSC required to reliably elicit an AP corresponds to an estimated 2-4 excitatory fibers. Note that this number represents a lower bound of required excitatory inputs to this system. 
The AP current threshold obtained from the experiments described above (Fig. 4) is more than twofold larger than previous reports have indicated (Scott et al., 2005; Chirila et al., 2007). In these earlier reports the current threshold was estimated from long step depolarizations, whereas the current thresholds derived from our experiments are based on EPSCs with extremely fast time courses (Fig. 2). To investigate the effect of these different stimulus waveforms on AP threshold, we performed whole-cell current-clamp recordings and injected either ramp stimuli (Fig. $5 A$ ) or $20 \mathrm{~ms}$ step depolarizations (Fig. $5 B$ ) of increasing amplitudes (from $500 \mathrm{pA}$ increasing in $100 \mathrm{pA}$ steps; $n=9$ ). To mimic the time course of mature EPSCs (Fig. 2), the ramp stimulus had a rise time of $150 \mu$ s and a decay time of 300 $\mu \mathrm{s}$. The voltage response to ramp stimuli was called a simulated EPSP (simEPSP). The AP current threshold for simEPSPs $(6.63 \pm 0.25 \mathrm{nA})$ was significantly higher $(p<0.05$, paired $t$ test) than that of the step responses $(4.26 \pm 0.12 \mathrm{nA}$; Fig. $5 A-$ $C)$, and in close agreement with the AP current thresholds derived from synaptic stimulation in Figure $4(8.0 \pm 1.7 \mathrm{nA})$. The remaining discrepancy between the AP current threshold estimates from ramp stimuli and synaptic stimulations can be attributed to the large quantal content of excitatory fibers and a lack of additional leak conductances that normally accompany synaptic inputs. Importantly, the change in AP current thresholds between the ramp and step stimuli cannot be explained by a change in voltage threshold as they are the same $(p>0.05$, paired $t$ test; $-36.64 \pm 2.26 \mathrm{mV}$ and $-34.87 \pm$ $2.02 \mathrm{mV}$ for ramp and step stimuli respectively; Fig. 5D).

In general, the resting membrane potential of these cells also remained constant between step $(-50.93 \pm 1.16 \mathrm{mV})$ and ramp $(-51.04 \pm 1.13 \mathrm{mV})$ current injections $(p>0.05$, paired $t$ test). We calculated the input resistance of these neurons $(4.95 \pm 0.85 \mathrm{M} \Omega)$ and the membrane time constant $(305.78 \pm 74.29 \mu \mathrm{s})$ using an exponential fit to the initial decay of an average (400 repetitions at $-5 \mathrm{pA}$ ) hyperpolarizing step (Fig. $5 E ; n=8$ ). These data were further used to estimate the average cell capacitance (69.82 \pm $12.80 \mathrm{pF}$ ), a number in close agreement with previous morphological estimates (Rautenberg et al., 2009).

To confirm the classification of EPSPs and APs based on peak and AHP thresholds (Fig. $4 B$ ), these parameters were also analyzed for the ramp simEPSPs (Fig. $5 F$ ).
A
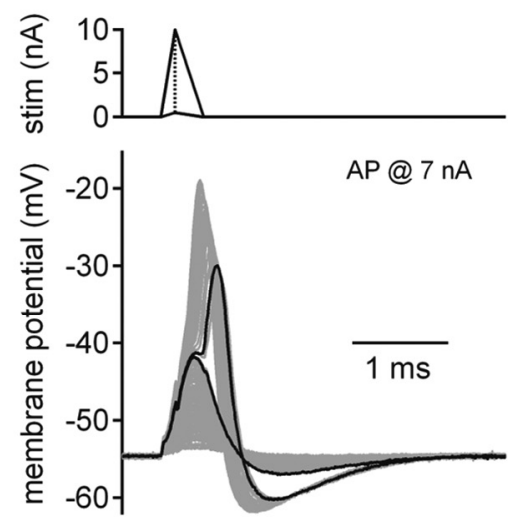

C

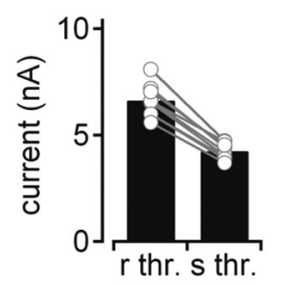

D



F



G

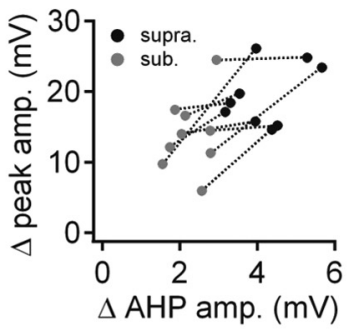

$\mathrm{H}$

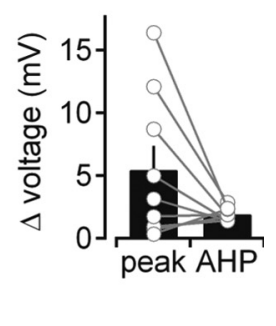

I

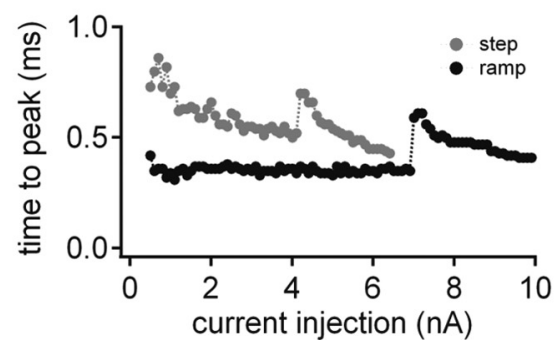

$J$



Figure 5. Influence of stimulus waveform on AP current thresholds. All sample data traces are from one cell. $\boldsymbol{A}$, Top, Schematic of the smallest $(500 \mathrm{pA})$ and largest $(10 \mathrm{nA})$ ramp stimuli used below. Bottom, Whole-cell current-clamp simEPSP responses to the full range of ramp stimulus amplitudes. Black traces are the simEPSPs either side of threshold (7 nA). B, Top, Schematic of the smallest $(500 \mathrm{pA})$ and largest $(6.4 \mathrm{nA})$ step stimuli used below. Bottom, Membrane voltage deflections to the full range of step stimulus amplitudes. Black traces are the responses either side of threshold (4.2 nA). Inset, Extended time course of the initial part of the step responses. $\boldsymbol{C}, \boldsymbol{D}$, Current $(\boldsymbol{C})$ and voltage $(\boldsymbol{D})$ thresholds for AP generation using ramp ( $r$ thr.) and step (s thr.) stimuli. Linked open symbols correspond to single-cell values, bar graphs are population average. $\boldsymbol{E}$, Input resistance (left) and membrane time constants (right). Open symbols correspond to single-cell values, bar graphs are population average. Inset, Example of an average response to the stimulus (see text; black trace) and the exponential fit used to calculate the time constant and input resistance (white trace, $n=8$ ). $\boldsymbol{F}$, Peak (filled circles) and AHP (open circles) amplitudes of traces in $\boldsymbol{A}$, plotted versus the peak of the ramp stimulus. A sudden jump in membrane potential occurs at AP threshold. $\mathbf{G}$, The peak versus AHP amplitudes as $\Delta$ from $V_{\text {rest }}$ of the simEPSPs either side of threshold for all cells. Gray circles are subthreshold (sub.), black circles are suprathreshold (supra.) responses, connected for each cell. $\boldsymbol{H}, \Delta$ voltage for peak and AHP amplitudes shown in $\boldsymbol{G}$. Linked open symbols correspond to single-cell values, bar graphs represent the population average. $I$, The time to peak (from stimulus onset) of $\operatorname{simEPSPS}$ in $\boldsymbol{A}$ (ramp, black circles) and membrane voltage deflections in $\boldsymbol{B}$ (step, gray circles) plotted versus the injected current. $\boldsymbol{J}$, Peak times as in $I$, averaged across all cells for subthreshold responses. Dotted lines indicate respective current thresholds; open circles are responses after the average threshold $(n=9)$. 
A


D

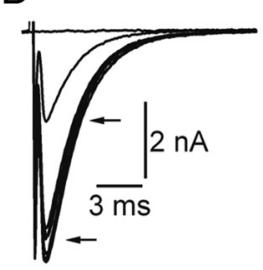

$\mathrm{E}$



$\mathrm{F}$
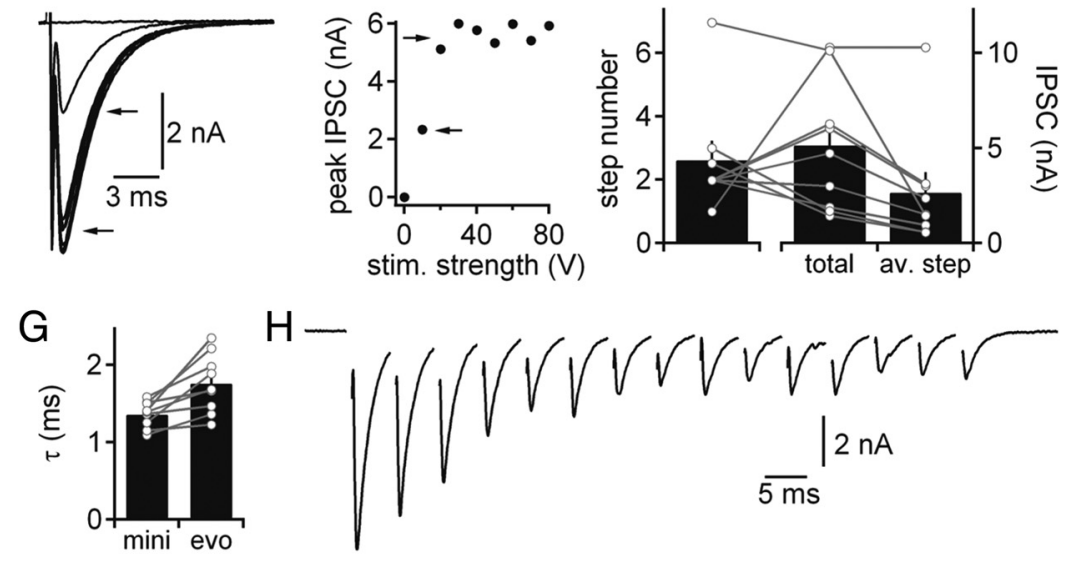

$\mathrm{H}-$
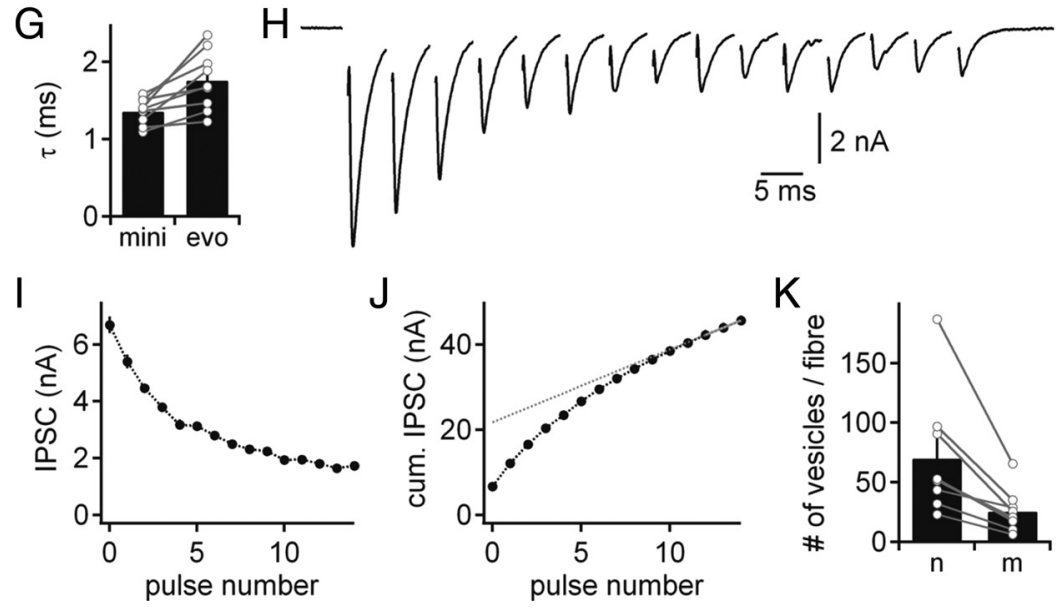

Figure 6. Determination of the inhibitory input strength. All sample data traces are from one cell. $A$, Sample trace for recording of mIPSCs. B, mIPSC peak distribution. Solid line corresponds to a Gaussian fit. $\boldsymbol{C}$, The extracted mIPSC (gray traces) and the average mIPSC (black trace). D, Sample traces of IPSCs evoked at different stimulation intensities. $\boldsymbol{E}$, IPSC amplitude as a function of stimulation strength from the sample traces shown in $\boldsymbol{D}$. Arrows in $\boldsymbol{D}$ and $\boldsymbol{E}$ indicate the step-like increase induced by a change in stimulation intensity. $\boldsymbol{F}$, The estimated step number, the current of the maximal step, the total maximal current and the calculated average current for an average step are shown for each neuron (open symbols) and for the population average (bar). G, Decay time of the average mIPSC from each cell and of IPSCs evoked with a 60-70 V stimulus pulse (open symbols). Population average is represented by underlying bar graph. $\boldsymbol{H}$, Sample trace of the pool depletion protocol; 15 pulses applied at $200 \mathrm{~Hz}$. I, Peak IPSC amplitudes as a function of pulse number from the stimulation train shown in $\boldsymbol{H}$. J, Cumulative IPSC amplitudes of the depression profile in $\boldsymbol{I}$. Line fit to the last 3 pulses (gray solid line) was used to estimate the total available IPSC amplitude (dotted line). $\boldsymbol{K}$, The estimated average pool of vesicles for an average inhibitory fiber to a given cell $(n)$ and the corresponding number of vesicles released by an average single fiber $(m)$. Open symbols correspond to single-cell values, bar graphs represent the population average $(n=9)$.

As with the recordings in Figure 4, the peaks and AHP amplitudes of the simEPSPs either side of AP threshold separated the events of each cell into 2 distinct groups (Fig. 5G). Importantly, the change in AHP amplitude was the most consistently accurate indicator for detecting AP generation (Fig. 5G,H).

An analysis of the time from the onset of the ramp stimuli to the peak of simEPSPs (time to peak) revealed it remained constant with increasing stimulus current (from $326.30 \pm 17.10 \mu \mathrm{s}$ to $318.90 \pm 24.53 \mu \mathrm{s}, p>0.05$, paired $t$ test). These time to peak values (Fig. $5 I, J$ ) are strikingly similar to the membrane time constant (Fig. $5 E ; p>0.05$ ). This indicates that the peak of the simEPSP is most likely unaffected by active conductances (Fig. 5J, black trace). In contrast, the time to peak of the membrane potential deflections elicited by step depolarizations sped up (from $769.17 \pm 129.95 \mu$ s to $436.67 \pm 8.33 \mu \mathrm{s}, p<0.05$, paired $t$ test), revealing an influence of additional active conductances (Fig.
$5 I, J)$. Note that the time to peak for just subthreshold responses to the step current injections was $\sim 100 \mu$ s longer than responses to ramp stimuli (Fig. $5 J$ ). This can effectively decrease the AP current threshold by allowing the membrane to charge over a longer period of time.

\section{The size of inhibitory fibers to MSO neurons}

After determining the fiber size, release probability and physiological strength of excitatory fibers, we sought to obtain similar estimates for the inhibitory inputs. This will enable us to determine whether the balance between excitation and inhibition observed during STP also holds for synaptic strength. We therefore repeated the same experiments as for the AMPA-R-mediated EPSCs (Fig. 3) for pharmacologically isolated glycinergic IPSCs (Fig. 6).

Amplitude distributions of extracted mIPSC were characteristically skewed (Fig. $6 A, B)$, with a CV of $0.63 \pm 0.04(n=$ 9), similar to previous reports (Smith et al., 2000). Due to this skew, we took the peak amplitude and decay of the average mIPSC from each cell (Fig. $6 C$ ), yielding a population average peak of $88 \pm 12 \mathrm{pA}$ and decay time constant of $1.36 \pm 0.06$ ms. We next estimated the strength of an average inhibitory fiber (Fig. $6 D-F$ ). On average, $2.6 \pm 0.6$ fibers were recruited at each stimulation site (Fig. 6 F). The maximal evoked fiber current was $5.1 \pm 1.3 \mathrm{nA}$ (data not shown) and the average current calculated for a single fiber was $2.7 \pm 1.1$ nA (Fig. $6 D-F$ ). These findings were corroborated with minimal stimulation experiments $(3.2 \pm 0.8 \mathrm{nA}$; supplemental Fig. S3, available at www.jneurosci.org as supplemental material). Again, we could estimate the quantal content of an average fiber since the decay time constants for mIPSCs and evoked IPSCs (1.76 \pm 0.13 ) were not significantly different (Fig. $6 G$; $p>0.05$ ). The average quantal content was $26 \pm 6$ vesicles (Fig. $6 \mathrm{~K}$ ). The pool depletion paradigm was used to investigate the number of available inhibitory vesicles (Fig. $6 H, I$ ). By calculating from the IPSC depression curves (Fig. 6I) the cumulative maximal current amplitude (Fig. $6 \mathrm{~J}$ ), we determined an average apparent pool of $70 \pm 18$ vesicles per fiber (Fig. $6 \mathrm{~K}$ ). Therefore, the average pool of vesicles of an excitatory fiber is $\sim 1.6$ times that of an inhibitory fiber. However, the calculated inhibitory release probability of $0.38 \pm 0.04$ was not significantly different from the excitatory inputs $(p>0.05)$.

To allow for a physiologically relevant comparison of excitatory and inhibitory fiber strengths, we estimated the synaptic conductance $(\mathrm{G})$ of the average fibers using the driving force for the respective synaptic currents (see Materials and Methods) and the actual current amplitudes. We calculate a mEPSG of $0.75 \pm$ $0.5 \mathrm{nS}$ and an excitatory fiber conductance of $37 \pm 4 \mathrm{nS}$. Thus 
$\sim 90 \mathrm{nS}$ of excitatory drive are required to elicit an AP. In comparison, we find an average mIPSG of $1.96 \pm 0.27 \mathrm{nS}$, and an inhibitory fiber conductance of $58 \pm 24$ $\mathrm{nS}$. Thus, despite the smaller pool size and quantal content of inhibitory fibers, their average fiber conductance exceeds the excitatory average conductance by $\sim 1.6$-fold.

Next we sought to correlate our physiological estimates of the inhibitory input strength with the anatomy of the MSO inputs. Given single inhibitory inputs have a quantal content of $\sim 25$ and a release probability of $\sim 0.4$, each is expected to contain $\sim 60$ release sites. EM studies identified up to three active zones in a single inhibitory bouton/varicosity (Clark, 1969; Lindsey, 1975; Kiss and Majorossy, 1983; Brunso-Bechtold et al., 1990; Kapfer et al., 2002). We therefore assume an average of 2-3 active zones per synapse, meaning each inhibitory fiber must possess 20-30 varicosities. To confirm this, we use single-cell electroporation of MNTB principal neurons, identified by their calyceal input (Fig. 7C). In total we reconstructed 8 fibers that terminated in the MSO with a total of 28 final branch segments (Fig. 7). All terminals targeted to the MSO were axon collaterals of fibers that save one, passed ventrally or dorsally the MSO. The axon collaterals terminated in several branches of $\sim 85 \mu \mathrm{m}$ in length, often in an arrangement parallel to the dendritic axis (medial-lateral) of the MSO (Fig. $7 B, C$ ). Final branches had an intertip distance of $\sim 35 \mu \mathrm{m}$ (Fig. $7 D$ ), suggesting that each branch terminated on a single MSO neuron, since MSO somas are perpendicularly spaced (dorsal-ventral) $\sim 15 \mu \mathrm{m}$ apart (Rautenberg et al., 2009). We counted the number of swellings in the MSO region of each branch and fiber, assuming that these swellings correspond to presynaptic varicosities as they appear identical to those identified in other regions of the brain (Shepherd et al., 2002; Zeilhofer et al., 2005). We counted 24-93 varicosities in the MSO region per fiber, with an average of $18 \pm 1.2$ per final branch (Fig. $7 E$ ). Together with the ultrastructural evidence for multiple release sites per synapse (Clark, 1969; Lindsey, 1975; Kiss and Majorossy, 1983; Brunso-Bechtold et al., 1990; Kapfer et al., 2002), this anatomically derived number matches well our physiological estimates of the number of presynaptic inhibitory release sites. Furthermore, we confirmed that one MNTB fiber innervates between 1 and 7 MSO neurons (Werthat et al., 2008).

We next determined the number of MNTB fibers that converge onto a single MSO neuron. To do so, we established an immunohistochemical marker that identifies MNTB neurons and their synapse location at MSO neurons, namely CB. First, inhibitory terminals were detected with colabeling for GlyT2 (Zafra et al., 1995; Friauf et al., 1999; Zeilhofer et al., 2005) and SV2, a presynaptic marker (Fig. $8 \mathrm{~A}$ ). We find that this inhibitory colabeling is mainly restricted to the soma of MSO cells (Clark,
1969; Kapfer et al., 2002). Similarly, there was substantial overlay of $\mathrm{CB}$ and GlyT2 at somatic regions (Fig. $8 \mathrm{~B}$ ). In contrast, CR only rarely colocalized with GlyT2, localizing instead to dendritic processes (Fig. 8C). This suggests that CB labels glycinergic inputs while $\mathrm{CR}$ is associated with nonglycinergic inputs. This differential expression was confirmed by a lack of colocalization of these two proteins (Fig. 8D). We furthermore show that the expression of $\mathrm{CB}$ and $\mathrm{CR}$ is restricted to presynaptic regions by their colabeling with presynaptic markers SV2 (Fig. 8E) and Rab3A (Fig. $8 F$ ). We find that the inhibitory calbindinergic input to the MSO derives predominantly from the MNTB, as excitatory fibers and nearly all cells in the LNTB express only parvalbumin and calretinin (Fig. 8G-I). Our characterization therefore establishes $\mathrm{CB}$ as an immunohistochemical marker that faithfully detects inhibitory inputs to MSO neurons.

Having established CB as a marker for predominantly MNTBderived inhibitory inputs, we next estimated the number of inhibitory presynaptic varicosities by counting CB- and SV2positive puncta on MSO neurons. We digitally extracted single MSO neurons $(n=7)$ and marked and counted all CB- and SV2-positive varicosities (Fig. $8 \mathrm{~J}$ ). On average, each MSO neuron had $47 \pm 4$ presynaptic inhibitory varicosities (Fig. $8 \mathrm{~K}$, inset). 

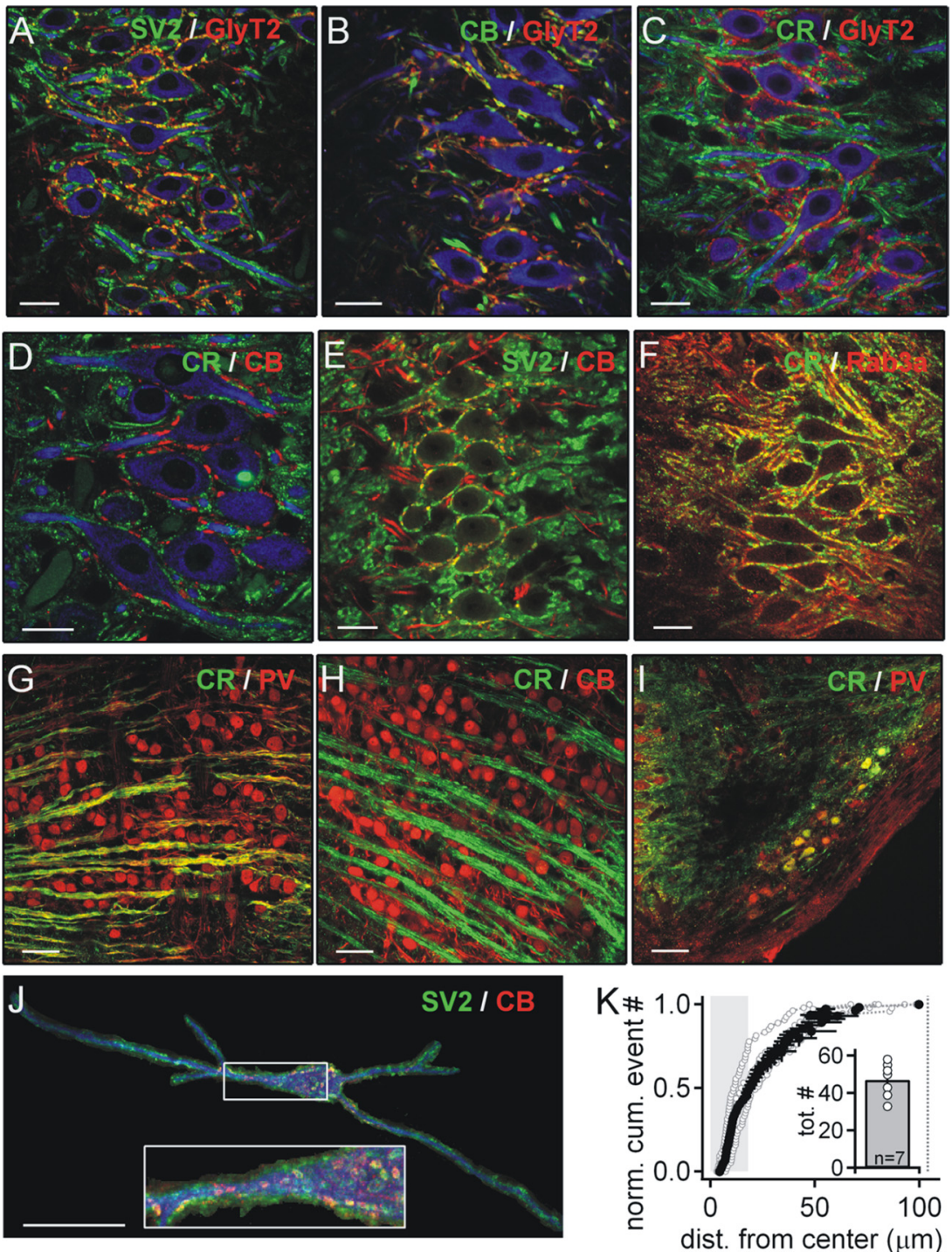

Figure 8. Quantification of number and location of inhibitory inputs to the MSO. $\boldsymbol{A}-\boldsymbol{C}$, Inhibitory presynaptic terminals are identified by SV2 and GlyT2 colocalization $(\boldsymbol{A})$ and are shown to be calbindinergic (CB) (B) but not calretinergic (CR) (C).D-F, CB and CR mark segregated presynaptic terminals $(\boldsymbol{D})$ of different inputs $(\boldsymbol{E}, \boldsymbol{F})$. Colors as in figure labels; blue corresponds to MAP-2 staining. $\boldsymbol{G}, \boldsymbol{H}$, MNTB neurons express PV $(\boldsymbol{G})$ and $C B$ but not $C R(\boldsymbol{H}) . \boldsymbol{I}, \mathrm{LNTB}$ cells are mainly $C R$ and PV positive. PV-stained cells on the left are MSO neurons. J, Digitally extracted single MSO neuron; inset shows a zoom of the perisomatic region. Inhibitory inputs colabel for (B and SV2. $\boldsymbol{K}$, Normalized distribution of the calbindinergic presynaptic varicosities as a function of distance (dist.) from soma center (black symbols correspond to the average distribution, open symbols represent single cells; $n=7$ ). Dotted line indicates average dendritic length. Inset shows the number of calbindinergic presynaptic varicosities. norm. cum. event, Normalized cumulative event. Scale bars: $\boldsymbol{A}-\boldsymbol{F}, \boldsymbol{J}, 20 \mu \mathrm{m} ; \mathbf{G}-\mathbf{I}, 50 \mu \mathrm{m}$

From normalized cumulative frequency histograms of presynaptic varicosity location (Fig. $8 \mathrm{~K}$ ), we found the distribution of CB-SV2 costained terminals had a length constant of $\sim 20 \mu \mathrm{m}$. Given an average somatic half length of $15.8 \pm 2.5 \mu \mathrm{m}$, it can be inferred that nearly $50 \%$ of all inhibitory inputs are targeted to the MSO soma. However, since a small fraction of CR-positive varicosities might be inhibitory (deriving from the LNTB) we also counted the number of GlyT2-positive terminals on digitally extracted MSO neurons (data not shown). We find an average of $55 \pm 4(n=7)$ GlyT2-positive terminals on MSO neurons. This finding confirms that the MNTB provides the dominant inhibitory input to the MSO, and that our methods provide a reliable estimate of inhibitory synaptic varicosity number.

From both our immunohistochemical and fiber tracing experiments, we find that each MSO neuron receives $\sim 50$ inhibi- tory varicosities, and that MNTB inputs to the MSO exhibit an average $\sim 18$ varicosities per final branch. Thus we estimate each MSO neuron receives input from 2 to 3 inhibitory fibers leading to a combined inhibitory conductance of $\sim 150 \mathrm{nS}$.

\section{Discussion}

This study provides new insight into the functioning of the fastest of all mammalian coincidence detectors. We find that coincidence detection in adult gerbils can occur with the integration of only 2-4 excitatory inputs. Both the excitatory and inhibitory inputs to the MSO are unusually strong and dynamically balanced, with a similar release probability and overall STP profile. Although single inhibitory fibers to MSO neurons impose a twofold larger conductance than excitatory fibers, we estimate from functional and anatomical data that each MSO neuron receives a minimum of $4-8$ excitatory inputs and 2-4 inhibitory inputs, resulting in an equal overall postsynaptic conductance for both excitatory and inhibitory inputs (see summary scheme in supplemental Fig. S4, available at www. jneurosci.org as supplemental material). Thus, coincidence detection in the MSO closely resembles that at upstream synapses in this circuit such as the endbulb of Held, and is strikingly dissimilar to octopus cells and neurons of the avian analog NL circuit. That different biophysical strategies are used by the MSO and the analog NL circuits is unsurprising given their independent evolution (Grothe, 2003).

It has been suggested that STD supports fast coincidence detection of different excitatory auditory inputs by an adaptive mechanism that preserves timedelay information (Kuba et al., 2002, 2006; Cook et al., 2003; Grau-Serrat et al., 2003; Ashida et al., 2007). In the mammalian MSO, inhibition is crucial for the proper tuning of ITD sensitivity (Brand et al., 2002; Pecka et al., 2008) and it has been suggested that precisely timed inhibitory drive sets the time window for neuronal coincidence detection (Pecka et al., 2008). Thus, if STD supports coincidence detection, and if the inhibitory inputs to the MSO are temporally aligned to the excitation, both the excitation and inhibition should have similar STP profiles. Here we describe a balance in MSO neurons between excitatory and inhibitory STP, defined as steady state, kinetics, and recovery from depression. This STP is most likely based on presynaptic factors such as pool depletion (Schneggenburger et al., 1999; Wu and Borst, 1999; Oleskevich et al., 2004; Yang and Xu-Friedman, 2008), $\mathrm{Ca}^{2+}$ current inactivation (Forsythe et al., 1998; Xu and Wu, 2005; Mochida et al., 2008; Müller et al., 2008), and recovery from depletion, possibly in a $\mathrm{Ca}^{2+}$-dependent manner (Dittman and Regehr, 1998; Wang and Kaczmarek, 1998; Wu and Borst, 1999; Hosoi et al., 2007; Yang and 
Xu-Friedman, 2008), since we found no indication of a postsynaptic contribution.

Presynaptically, excitatory and inhibitory fibers to the MSO achieve this balance with the expression of a different subset of fast buffering $\mathrm{Ca}^{2+}$ binding proteins. As in other mammals, the major $\mathrm{Ca}^{2+}$ binding protein in MSO neurons is parvalbumin (Vater and Braun, 1994; Caicedo et al., 1996; Lohmann and Friauf, 1996). We find inhibitory inputs are nearly exclusively parvalbuminergic and calbindinergic, whereas excitatory fibers express parvalbumin and calretinin. Thus, both input types appear equally well equipped with a fast and slow $\mathrm{Ca}^{2+}$ buffer, suggesting that $\mathrm{Ca}^{2+}$ buffering might contribute to the similarities observed in STP.

We experimentally compared the basal synaptic strength of excitatory and inhibitory inputs. Excitatory fibers release approximately twice as many vesicles from an apparent pool of 118 vesicles, double the size of that of inhibitory fibers. However, inhibitory vesicles impose a 2 - to 3 -fold larger conductance than excitatory vesicles, resulting in an equal overall conductance. The conductance imposed by the quantal contents of both inputs is large, comparable to an endbulb-type synapse (Oleskevich et al., 2004; Xu-Friedman and Regehr, 2005). The unusual strength of the inhibitory input speaks to the fundamental importance of inhibition in this circuit (Brand et al., 2002; Pecka et al., 2008). Moreover, our results are in accord with ultrastructural evidence from EM studies indicating multiple active zones in single excitatory and inhibitory varicosities (Clark, 1969; Lindsey, 1975; Kiss and Majorossy, 1983; Brunso-Bechtold et al., 1990; Kapfer et al., 2002). If we assume 2.5 active zones per presynaptic inhibitory varicosity, each fiber would contain $\sim 50$ active zones. This estimate fits well with our average pool estimate of 50 vesicles per inhibitory fiber.

From our data we estimate the overall inhibitory input and the minimally required amount of excitation for AP generation to an MSO neuron. We estimate from our anatomical data that 2-4 inhibitory fibers innervate each MSO neuron, conveying a total inhibitory conductance of 150-180 nS. We confirm that this inhibition is mainly targeted to the soma (Clark, 1969; Kapfer et al., 2002). Excitation onto bipolar MSO neurons, on the other hand, is compartmentalized according to the side of origin; contralateral excitation contacts the medial and ipsilateral excitation the lateral dendrite (Stotler, 1953). It is known that the excitatory drive onto one of these dendrites is sufficient to elicit an AP (Goldberg and Brown, 1969; Yin and Chan, 1990; Grothe and Sanes, 1993), which we estimate requires the simultaneous activation of 2-4 fibers with a total conductance of $\sim 90 \mathrm{nS}$. Thus it follows that at least $4-8$ excitatory fibers converge onto a single MSO neuron generating $\sim 180-200 \mathrm{nS}$ in total. An important caveat to the estimated excitatory fiber number required to generate an AP is that due to the substantial STD, it is likely that the convergence of more fibers are required to sustain ongoing activity. Our estimates therefore represent a lower bound for the number of excitatory fibers required for AP generation. The corresponding synaptic currents that are required for AP generation were found to be larger than previously estimated (Scott et al., 2005; Chirila et al., 2007). However, the estimate was confirmed by recording voltage responses elicited by finely graded simulated EPSCs with fast time courses that mimic the actual EPSC waveforms generated in the MSO. The unexpected invariance of the time to peak of the simEPSP illustrates the importance of using the appropriate kinetics of inputs to investigate their summation and its effects on the microsecond scale coincidence detection in this nucleus.
Taken together, our data demonstrates that the circuit encoding azimuthal localization of low-frequency sound sources requires a minimal number of excitatory and inhibitory inputs with balanced STP. In contrast to octopus cells and models of the MSO/NL (Kempter et al., 1998; Brand et al., 2002; Cook et al., 2003; Grau-Serrat et al., 2003; Kuba et al., 2006; Ashida et al., 2007), only 2-4 large excitatory fibers per dendrite and 2-4 somatically located inhibitory fibers are required. The presence of highly specialized inputs to the MSO with unusually large and fast synaptic conductances fits well with the overall synaptic architecture of this binaural coincidence detection circuit.

\section{References}

Agmon-Snir H, Carr CE, Rinzel J (1998) The role of dendrites in auditory coincidence detection. Nature 393:268-272.

Ashida G, Abe K, Funabiki K, Konishi M (2007) Passive soma facilitates submillisecond coincidence detection in the owl's auditory system. J Neurophysiol 97:2267-2282.

Brand A, Behrend O, Marquardt T, McAlpine D, Grothe B (2002) Precise inhibition is essential for microsecond interaural time difference coding. Nature 417:543-547.

Brunso-Bechtold JK, Henkel CK, Linville C (1990) Synaptic organization in the adult ferret medial superior olive. J Comp Neurol 294:389-398.

Caicedo A, d'Aldin C, Puel JL, Eybalin M (1996) Distribution of calciumbinding protein immunoreactivities in the guinea pig auditory brainstem. Anat Embryol (Berl) 194:465-487.

Chirila FV, Rowland KC, Thompson JM, Spirou GA (2007) Development of gerbil medial superior olive: integration of temporally delayed excitation and inhibition at physiological temperature. J Physiol 584:167-190.

Clark GM (1969) The ultrastructure of nerve endings in the medial superior olive of the cat. Brain Res 14:293-305.

Cook DL, Schwindt PC, Grande LA, Spain WJ (2003) Synaptic depression in the localization of sound. Nature 421:66-70.

Dittman JS, Regehr WG (1998) Calcium dependence and recovery kinetics of presynaptic depression at the climbing fiber to Purkinje cell synapse. J Neurosci 18:6147-6162.

Forsythe ID, Tsujimoto T, Barnes-Davies M, Cuttle MF, Takahashi T (1998) Inactivation of presynaptic calcium current contributes to synaptic depression at a fast central synapse. Neuron 20:797-807.

Friauf E, Aragón C, Löhrke S, Westenfelder B, Zafra F (1999) Developmental expression of the glycine transporter GLYT2 in the auditory system of rats suggests involvement in synapse maturation. J Comp Neurol 412:17-37.

Goldberg JM, Brown PB (1969) Response of binaural neurons of dog superior olivary complex to dichotic tonal stimuli: some physiological mechanisms of sound localization. J Neurophysiol 32:613-636.

Golding NL, Robertson D, Oertel D (1995) Recordings from slices indicate that octopus cells of the cochlear nucleus detect coincident firing of auditory nerve fibers with temporal precision. J Neurosci 15:3138-3153.

Grau-Serrat V, Carr CE, Simon JZ (2003) Modeling coincidence detection in nucleus laminaris. Biol Cybern 89:388-396.

Grothe B (2003) New roles for synaptic inhibition in sound localization. Nat Rev Neurosci 4:540-550.

Grothe B, Sanes DH (1993) Bilateral inhibition by glycinergic afferents in the medial superior olive. J Neurophysiol 69:1192-1196.

Hosoi N, Sakaba T, Neher E (2007) Quantitative analysis of calciumdependent vesicle recruitment and its functional role at the calyx of Held synapse. J Neurosci 27:14286-14298.

Joris PX, Carney LH, Smith PH, Yin TC (1994) Enhancement of neural synchronization in the anteroventral cochlear nucleus. I. Responses to tones at the characteristic frequency. J Neurophysiol 71:1022-1036.

Kapfer C, Seidl AH, Schweizer H, Grothe B (2002) Experience-dependent refinement of inhibitory inputs to auditory coincidence-detector neurons. Nat Neurosci 5:247-253.

Kempter R, Gerstner W, van Hemmen JL, Wagner H (1998) Extracting oscillations. Neuronal coincidence detection with noisy periodic spike input. Neural Comput 10:1987-2017.

Kiss A, Majorossy K (1983) Neuron morphology and synaptic architecture in the medial superior olivary nucleus. Light- and electron microscope studies in the cat. Exp Brain Res 52:315-327.

Kuba H, Koyano K, Ohmori H (2002) Synaptic depression improves coin- 
cidence detection in the nucleus laminaris in brainstem slices of the chick embryo. Eur J Neurosci 15:984-990.

Kuba H, Ishii TM, Ohmori H (2006) Axonal site of spike initiation enhances auditory coincidence detection. Nature 444:1069-1072.

Lindsey BG (1975) Fine structure and distribution of axon terminals from the cochlear nucleus on neurons in the medial superior olivary nucleus of the cat. J Comp Neurol 160:81-103.

Lohmann C, Friauf E (1996) Distribution of the calcium-binding proteins parvalbumin and calretinin in the auditory brainstem of adult and developing rats. J Comp Neurol 367:90-109.

Magnusson AK, Kapfer C, Grothe B, Koch U (2005) Maturation of glycinergic inhibition in the gerbil medial superior olive after hearing onset. J Physiol 568:497-512.

Mochida S, Few AP, Scheuer T, Catterall WA (2008) Regulation of presynaptic $\mathrm{Ca}(\mathrm{V}) 2.1$ channels by $\mathrm{Ca}^{2+}$ sensor proteins mediates short-term synaptic plasticity. Neuron 57:210-216.

Müller M, Felmy F, Schneggenburger R (2008) A limited contribution of $\mathrm{Ca}^{2+}$ current facilitation to paired-pulse facilitation of transmitter release at the rat calyx of Held. J Physiol 586:5503-5520.

Oertel D, Bal R, Gardner SM, Smith PH, Joris PX (2000) Detection of synchrony in the activity of auditory nerve fibers by octopus cells of the mammalian cochlear nucleus. Proc Natl Acad Sci U S A 97:11773-11779.

Oleskevich S, Youssoufian M, Walmsley B (2004) Presynaptic plasticity at two giant auditory synapses in normal and deaf mice. J Physiol 560: 709-719.

Pecka M, Brand A, Behrend O, Grothe B (2008) Interaural time difference processing in the mammalian medial superior olive: the role of glycinergic inhibition. J Neurosci 28:6914-6925.

Rautenberg PL, Grothe B, Felmy F (2009) Quantification of the threedimensional morphology of coincidence detector neurons in the medial superior olive of gerbils during late postnatal development. J Comp Neurol 517:385-396.

Reyes AD, Rubel EW, Spain WJ (1996) In vitro analysis of optimal stimuli for phase-locking and time-delayed modulation of firing in avian nucleus laminaris neurons. J Neurosci 16:993-1007.

Schneggenburger R, Meyer AC, Neher E (1999) Released fraction and total size of a pool of immediately available transmitter quanta at a calyx synapse. Neuron 23:399-409.

Scott LL, Mathews PJ, Golding NL (2005) Posthearing developmental refinement of temporal processing in principal neurons of the medial superior olive. J Neurosci 25:7887-7895.
Shepherd GM, Raastad M, Andersen P (2002) General and variable features of varicosity spacing along unmyelinated axons in the hippocampus and cerebellum. Proc Natl Acad Sci U S A 99:6340-6345.

Smith AJ, Owens S, Forsythe ID (2000) Characterisation of inhibitory and excitatory postsynaptic currents of the rat medial superior olive. J Physiol 529:681-698.

Stotler WA (1953) An experimental study of the cells and connections of the superior olivary complex of the cat. J Comp Neurol 98:401-431.

Taschenberger H, Scheuss V, Neher E (2005) Release kinetics, quantal parameters and their modulation during short-term depression at a developing synapse in the rat CNS. J Physiol 568:513-537.

Vater M, Braun K (1994) Parvalbumin, calbindin D-28k, and calretinin immunoreactivity in the ascending auditory pathway of horseshoe bats. J Comp Neurol 341:534-558.

Wang LY, Kaczmarek LK (1998) High-frequency firing helps replenish the readily releasable pool of synaptic vesicles. Nature 394:384-388.

Werthat F, Alexandrova O, Grothe B, Koch U (2008) Experiencedependent refinement of the inhibitory axons projecting to the medial superior olive. Dev Neurobiol 68:1454-1462.

Wu LG, Borst JG (1999) The reduced release probability of releasable vesicles during recovery from short-term synaptic depression. Neuron 23:821-832.

$\mathrm{Xu} \mathrm{J,} \mathrm{Wu} \mathrm{LG} \mathrm{(2005)} \mathrm{The} \mathrm{decrease} \mathrm{in} \mathrm{the} \mathrm{presynaptic} \mathrm{calcium} \mathrm{current} \mathrm{is} \mathrm{a}$ major cause of short-term depression at a calyx-type synapse. Neuron 46:633-645.

Xu-Friedman MA, Regehr WG (2005) Dynamic-clamp analysis of the effects of convergence on spike timing. II. Few synaptic inputs. J Neurophysiol 94:2526-2534.

Yang H, Xu-Friedman MA (2008) Relative roles of different mechanisms of depression at the mouse endbulb of Held. J Neurophysiol 99:2510-2521.

Yin TC, Chan JC (1990) Interaural time sensitivity in medial superior olive of cat. J Neurophysiol 64:465-488.

Zafra F, Aragón C, Olivares L, Danbolt NC, Giménez C, Storm-Mathisen J (1995) Glycine transporters are differentially expressed among CNS cells. J Neurosci 15:3952-3969.

Zeilhofer HU, Studler B, Arabadzisz D, Schweizer C, Ahmadi S, Layh B, Bösl MR, Fritschy JM (2005) Glycinergic neurons expressing enhanced green fluorescent protein in bacterial artificial chromosome transgenic mice. J Comp Neurol 482:123-141. 